\title{
Biomechanical analysis of the FlatWire Figure 8 sternal fixation device
}

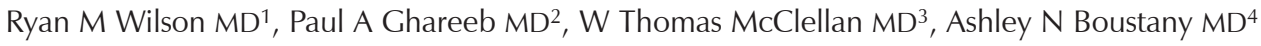

RM Wilson, PA Ghareeb, WT McClellan, AN
Boustany. Biomechanical analysis of the FlatWire
Figure 8 sternal fixation device. Plast Surg 2014;22(3):188-190.

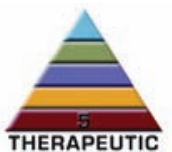

OBJECTIVE: To determine whether the FlatWire Figure 8 sternal fixation device (Penn United, USA) is mechanically superior to the current standard in sternotomy closure.

DESCRIPTION: Unstable sternal closure using traditional steel-wire cerclage can increase postoperative pain, bony cut-through and wound dehiscence. The authors present the Figure 8 sternal fixation device to minimize these complications. Biomechanical properties of the device were compared with conventional steel wire sternal repair.

EVALUATION: Using two constructs of both FlatWire and steel wire, pull-to-failure, Hertzian contact and cut-through were compared. Samples were tested to 500,000 cycles or failure. Cyclic comparisons were performed using log-rank $t$ tests and Student's $t$ tests for cut-through analysis. FlatWires were found to have superior biomechanical properties in all categories tested.

CONCLUSION: The FlatWire provides superior biomechanical properties compared with conventional steel wire, which may lead to reduced sternal wound complications.

Key Words: Figure 8; FlatWire; Sternal fixation; Sternal wound; Sternotomy
The consequences of sternal separation, cut-through or dehiscence 1 can be profound, with a mortality rate of $10 \%$ to $40 \%$ (1). The risk of complications increases in complex comorbid patients and in the elderly (2,3). These complications include dehiscence, osteomyelitis, mediastinitis, sternal nonunion and chronic sternal pain, with sternal instability playing a major role. The physiological forces exerted, even with heavy coughing ( $400 \mathrm{~N}$ to $1200 \mathrm{~N}$ ), have been to shown destabilize sternal closure and result in bone cut through or displacement (4). Addressing this issue can ultimately reduce mortality, morbidity, hospital stay, overall costs and the psychological distress involved.

The most important factor in the prevention of sternal events is a stable sternal approximation following sternotomy $(5,6)$. There have been many attempts to improve the standard method of steel wire cerclage; however, these systems have failed to gain widespread adoption. The FlatWire Figure 8 sternal fixation device (Penn United, USA) was developed to provide a sternal closure method that is superior to standard steel wire cerclage, while avoiding the flaws of current alternatives. The purpose of the present study was to examine the mechanical properties of FlatWires and standard steel wire sternal cerclage by comparing pull-to-failure, Hertzian contact and cut-through.

FlatWires demonstrate superior mechanical properties and reduced cut-through while maintaining the simplicity and low cost of steel wires. They are made from 316 L stainless steel, and are applied either

\section{Une analyse biomécanique du dispositif de fixation du sternum FlatWire Figure 8}

OBJECTIF : Déterminer si le dispositif de fixation du sternum FlatWire Figure 8 (Penn United, États-Unis) est mécaniquement supérieur à la norme actuelle pour la fermeture des sternotomies.

DESCRIPTION : La fermeture du sternum au moyen du cerclage classique en fil d'acier peut accroître la douleur postopératoire, l'insertion osseuse et la déhiscence de la plaie. Les auteurs présentent le dispositif de fixation du sternum Figure 8 pour réduire ces complications au minimum. Les auteurs ont comparé les propriétés biomécaniques du dispositif à la réparation sternale classique à l'aide d'un fil d'acier.

ÉVALUATION : Les auteurs ont comparé le test de tension, le contact hertzien et l'insertion du modèle FlatWire à celui du fil d'acier. Ils ont comparé les échantillons jusqu'à 500000 cycles ou jusqu'à l'échec. Les comparaisons cycliques ont été effectuées au moyen de tests $t$ de Mantel-Haenzel et de tests $t$ pour l'analyse de tension. Le modèle FlatWire avait des propriétés biomécaniques supérieures dans toutes les catégories mises à l'essai.

CONCLUSION : Le FlatWire a des propriétés biomécaniques supérieures à celles du fil d'acier classique, lesquelles peuvent réduire les complications de la plaie du sternum.

${ }^{1}$ University of Kentucky College of Medicine, Department of Plastic Surgery, Lexington, Kentucky; ${ }^{2}$ Emory University School of Medicine

Department of Surgery, Division of Plastic Surgery, Atlanta, Georgia; ${ }^{3}$ West Virginia University School of Medicine, Department of Surgery,

Division of Plastic Surgery, Morgantown, West Virginia; ${ }^{4}$ University of Kentucky College of Medicine, Department of Plastic Surgery,

Lexington, Kentucky, USA

Correspondence: Dr Ashley N Boustany, The United Center - 1085 Van Voorhis Road Suite 350, Morgantown, West Virginia 26505, USA.

Telephone 304-389-6690, fax 304-777-4679, e-mail anboustany@gmail.com 


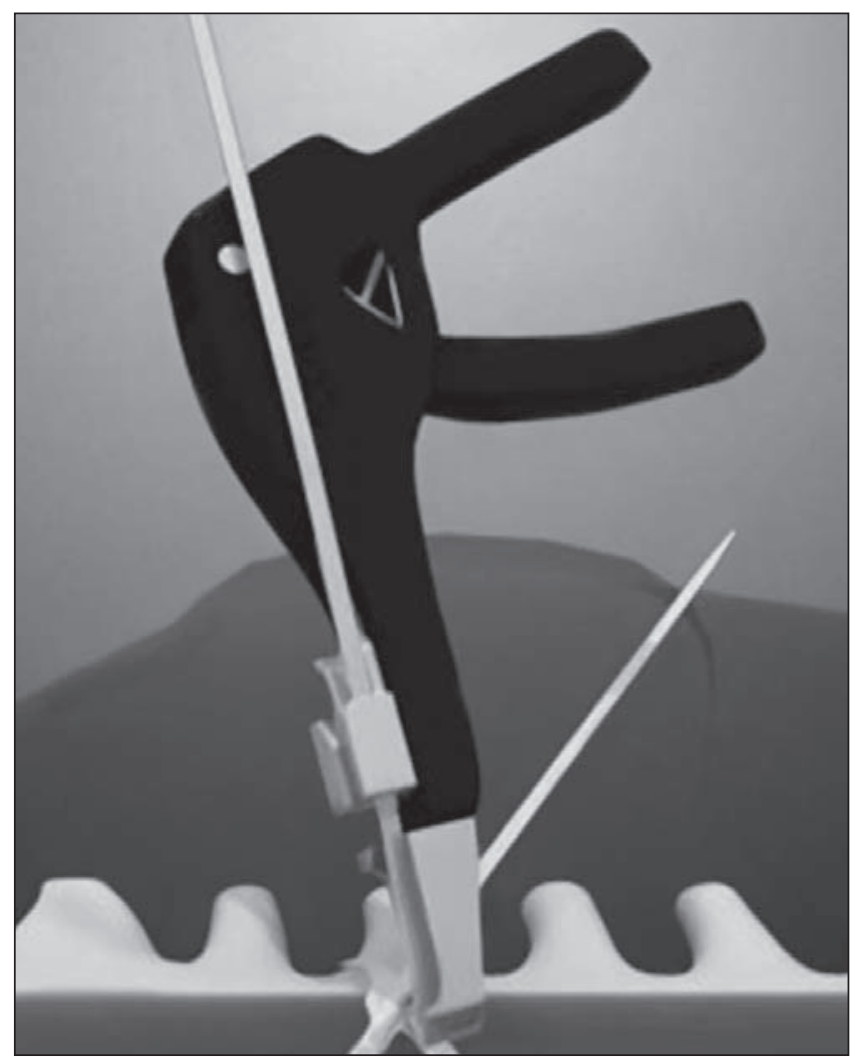

Figure 1) FlatWire Figure 8 (Penn United, USA) tensioning device. The Figure 8 device is placed in the tool, and the applicator is ratcheted using one hand until the desired tension is achieved

comparisons between groups and are more available and affordable than cadaveric sterna. Twenty-four PEEK sterna were divided into four groups of six. The figure 8 engineer placed the Figure 8 devices, while a board-certified cardiothoracic surgeon placed the Ethicon steel wires. Two fixtures from each of the four groups were then selected for ultimate tensile testing.

Fixtures were mounted to a servopneumatic cylinder (ELF 3230 EnduraTec, USA) for longitudinal shear testing. A longitudinal distraction force was cycled between $-100 \mathrm{~N}$ and $100 \mathrm{~N}$ at $2 \mathrm{~Hz}$ to $10 \mathrm{~Hz}$ for 500,000 cycles or until failure occurred. Failure was defined as breakage or displacement of $4 \mathrm{~mm}$ from zero load. Ultimate tensile strength was determined using a servopneumatic cylinder (series 3040 EnduraTec, USA) with pull-to-failure testing at a rate of $0.0038 \mathrm{~mm} / \mathrm{s}$. Cut-through was tested using artificial sterna molded from $20 \mathrm{lb} / \mathrm{ft}^{3}$ rigid polyurethane foam (1025-2, Pacific Research Laboratories Inc, USA) at a Food \& Drug Aministration-approved facility (Peridot, Pleasanton, California, USA). The models were hemisected longitudinally and secured to a base by simulated rib buds. Lateral distraction was applied with four forces separately along the sternal edge at intervals: $30 \mathrm{lbs}, 40 \mathrm{lbs}, 50 \mathrm{lbs}$ and $60 \mathrm{lbs}$. Force was applied with a digital force gauge (Imada Z2, USA) at $2 \mathrm{~mm} / \mathrm{s}$ distraction until the desired force was obtained and then held for $10 \mathrm{~s}$. A Mitutoyo Vision System (Quick Vision Elf, USA) (resolution $0.1 \mu \mathrm{m}$ ) measured depth of penetration.

Statistical analyses were performed using SAS version 9.2 (SAS Institute, USA); a log-rank test was used for cyclic comparisons and a Student's $t$ test for the cut-through analysis; $\mathrm{P}<0.05$ was considered to be statistically significant.

\section{RESULTS}

Both configurations of the Figure 8 sternal fixation device demonstrated superior strength and durability when compared with their steel wire (ST) counterparts.
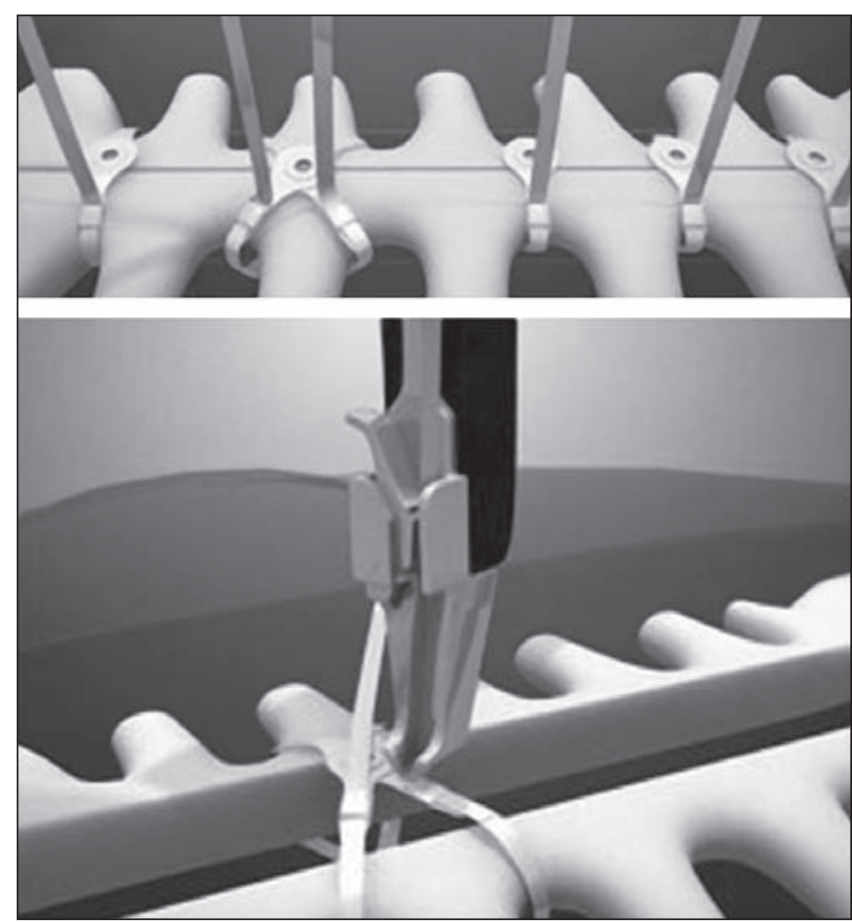

Figure 2) Figure 8 device cross (8DX) and Transverse (8DT) pattern (Penn United, USA) on the accepted polyurethane sternal bone analogue. The Figure 8 device crosses the sternum on both the anterior and posterior sides forming a rigid construct. The central stability hub enables device alignment even with variable rib and sternum sizes

In lateral distraction testing, the $8 \mathrm{DX}$ averaged $>500,000$ cycles to failure, compared with 189,157 for the $\mathrm{S} 8(\mathrm{P}<0.02)$. Average cycles to failure for the $8 \mathrm{DT}$ was 424,620 versus 63,926 for the steel ST $(\mathrm{P}<0.005)$ (Figure 3).

In longitudinal shear testing, the 8DX failed after 252,360 cycles on average versus 1139 for the $\mathrm{S} 8(\mathrm{P}<0.0005)$. Average cycles to failure for the 8DT was 98,561 versus 7380 for the ST $(P<0.02)$.

In ultimate tensile testing, the 8DX failed at an average of $960 \mathrm{~N}$ compared with $677 \mathrm{~N}$ for the S8. The 8DT failed at $1030 \mathrm{~N}$ versus $595 \mathrm{~N}$ for the ST.

The Figure 8 device demonstrated significantly less cut-through at all levels of force (Figure 4). At $30 \mathrm{lbs}, 40 \mathrm{lbs}, 50 \mathrm{lbs}$ and $60 \mathrm{lbs}$, mean cut-through depth was $0.229 \mathrm{~mm}, 0.356 \mathrm{~mm}, 0.482 \mathrm{~mm}$ and $0.889 \mathrm{~mm}$ for the Figure 8 device, respectively, versus $0.381 \mathrm{~mm}, 0.660 \mathrm{~mm}$, $1.372 \mathrm{~mm}$ and $2.591 \mathrm{~mm}$ for Ethicon $\# 5$ steel wire $(\mathrm{P}=0.024, \mathrm{P}=0.027$, $\mathrm{P}=0.026$ and $\mathrm{P} \leq 0.001$, respectively).

\section{DISCUSSION}

Sternal wound dehiscence and mediastinitis represent one of the gravest complications of median sternotomy (1). Despite an incidence of only $0.3 \%$ to $5 \%$ (7), $>760,000$ sternotomy procedures are performed every year, making this a serious problem. The median hospital costs for patients developing sternal wound complications following coronary artery bypass grafting surgery can be up to 2.8 times higher than for uncomplicated patients (8). The United States Department of Health and Human Services has identified these complications as hospitalacquired conditions for which hospitals should not receive additional payment if the condition was not present at admission (9).

Stainless steel wire is the most common method of sternal closure, but several flaws hinder its ability to provide a stable sternal approximation. The technique of application is imprecise and operator dependent, introducing variability. As the wire is twisted, sites of increased stress concentration are formed, predisposing to failure (10). The steel wire contacts the sternum over a small surface area, leading to sternal cut-through. 


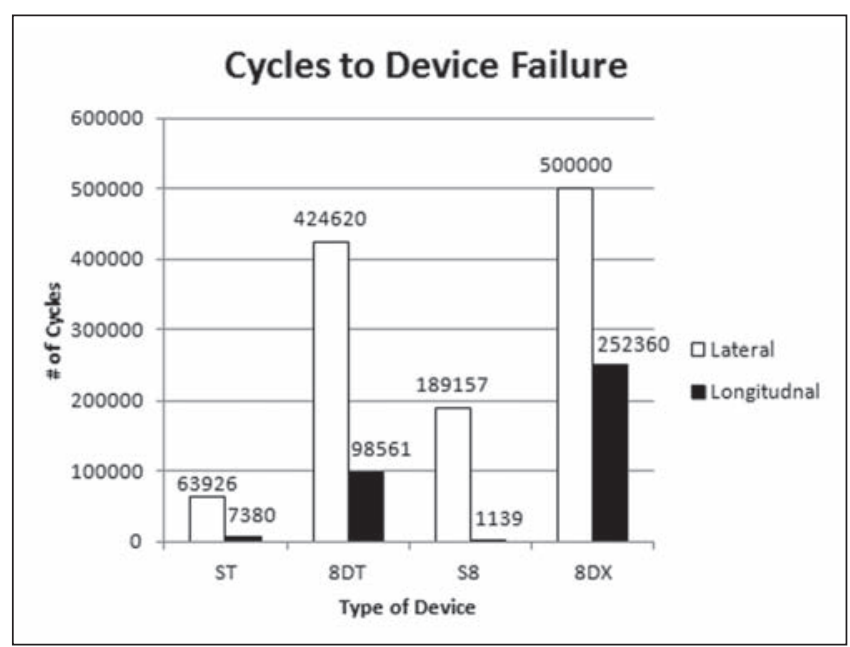

Figure 3) The Figure 8 transverse (8DT) and ' $X$ ' pattern (8DX) (Penn United, USA) were significantly stronger than their steel wire (ST) counterparts in both cyclic lateral and longitudinal distraction. Data presented as the mean number of cycles to failure. S8 Steel wire

Alternatives to steel wire fixation have been proposed, including rigid plate fixation, adhesives, cables and Mersilene tape. Although these constructs have shown sufficient strength in bench-top testing, they have failed to gain traction as a primary closure method due to a variety of reasons. Many of these systems require additional training to use and application of the systems result in increased operative times. In particular, sternal plating has been identified as a closure method that may improve outcomes; however, the cost and complexity of the system has reduced mainstream applicability (11). Rigid external fixation involves the use of metal plates and screws into the sternum itself. It carries significantly greater costs than standard wires; thus, it is typically used as a secondary procedure after complications have already occurred or in very high-risk patients. With this technique, there is the risk for screw migration and it is contraindicated in patients with poor bone quality. We present FlatWires as a method for primary closure as

\section{REFERENCES}

1. Shih CC, Shih CM, Su YY, Lin SJ. Potential risk of sternal wires. Eur J Cardiothorac Surg 2004;25:812-8.

2. Ståhle E, Tammelin A, Bergström R, Hambreus A, Nyström SO, Hansson HE. Sternal wound complications - incidence, microbiology and risk factors. Eur J Cardiothorac Surg 1997;11:1146-53.

3. Ridderstolpe L, Gill H, Granfeldt H, Ahlfeldt H, Rutberg H. Superficial and deep sternal wound complications: Incidence, risk factors and mortality. Eur J Cardiothorac Surg 2001;20:1168-75.

4. Losanoff JE, Collier AD, Wagner-Mann CC, et al. Biomechanical comparison of median sternotomy closures. Ann Thorac Surg 2004;77:203-9.

5. Casha AR, Gauci M, Yang L, Saleh M, Kay PH, Cooper GJ. Fatigue testing median sternotomy closures. Eur J Cardiothorac Surg 2001;19:249-53.

6. DiMarco RF, Lee MW, Bekoe S, Grant KJ, Woelfel G, Pellegrini RV. Interlocking figure-of- 8 closure of the sternum. Ann Thorac Surg 1989;47:927-9.

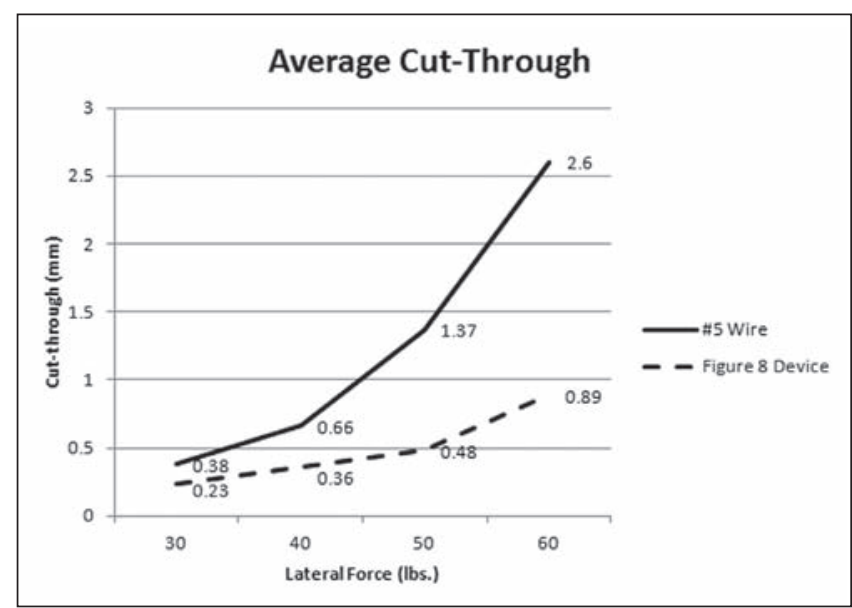

Figure 4) At all levels of force, the Figure 8 device (Penn United, USA) exhibited significantly reduced cut-through compared with steel wire

an alternative to standard wires. The cost-benefit ratio may prove favourable in the ongoing randomized controlled trial because FlatWires are priced significantly lower than rigid fixation.

\section{CONCLUSION}

The Figure 8 device attempts to ameliorate the weakness of steel wire cerclage while avoiding the flaws of current alternatives. The present study demonstrates that the Figure 8 device has superior mechanical properties to steel wire and may reduce complications such as sternal dehiscence and mediastinitis. A prospective randomized comparison is warranted.

ACKNOWLEDGEMENTS: The authors acknowledge that the technology used in this study was donated by Figure 8 Surgical Inc, and that no other funding was received by Figure 8 Surgical Inc. All authors had freedom of investigation from outside interests in this original research.

7. Losanoff JE, Richman BW, Jones JW. Disruption and infection of median sternotomy: A comprehensive review. Eur J Cardiothorac Surg 2002;21:831-9.

8. Loop FD, Lytle BW, Cosgrove DM, et al. J. Maxwell Chamberlain memorial paper: Sternal wound complications after isolated coronary artery bypass grafting: Early and late mortality, morbidity, and cost of care. Ann Thorac Surg 1990;49:179-86.

9. Department of Health and Human Services. 2010 Oct. HospitalAcquired Conditions (HAC) in Acute Inpatient Prospective Payment System (IPPS) Hospitals. <www.cms.gov/ HospitalAcqCond> (Accessed Febraury 20, 2011).

10. Wangsgard C, Cohen DJ, Griffin LV. Fatigue testing of three peristernal median sternotomy closure techniques. J Cardiothorac Surg 2008;3:52.

11. Snyder CW, Graham LA, Byers RE, Holman WL. Primary sternal plating to prevent sternal wound complications after cardiac surgery: Early experience and patterns of failure. Interact Cardiovasc Thorac Surg 2009;9:763-6. 